\title{
Advanced glycation end products are elevated in estrogen receptor- positive breast cancer patients, alter response to therapy, and can be targeted by lifestyle intervention
}

\author{
Katherine R. Walter ${ }^{1} \cdot$ Marvella E. Ford ${ }^{2,3,15} \cdot$ Mathew J. Gregoski ${ }^{4} \cdot$ Rita M. Kramer $^{3} \cdot$ Kendrea D. Knight $^{2}$. \\ Laura Spruill $^{1}$ - Lourdes M. Nogueira ${ }^{1}$. Bradley A. Krisanits ${ }^{1}$ - Van Phan ${ }^{1}$. Amanda C. La Rue ${ }^{1,3,5}$. \\ Michael B. Lilly ${ }^{1}$ Stefan Ambs ${ }^{6} \cdot$ King Chan $^{7}$. Tonya F. Turner ${ }^{8} \cdot$ Heidi Varner $^{2}$. Shweta Singh ${ }^{2}$. Jaime Uribarri ${ }^{9}$. \\ Elizabeth Garrett-Mayer ${ }^{2,3} \cdot$ Kent E. Armeson ${ }^{2,3}$. Ebony J. Hilton ${ }^{10}$. Mark J. Clair ${ }^{11}$ - Marian H. Taylor ${ }^{11}$. \\ Andrea M. Abbott ${ }^{12}$. Victoria J. Findlay ${ }^{1,2} \cdot$ Lindsay L. Peterson $^{13} \cdot$ Gayenell Magwood $^{14} \cdot$ David P. Turner $^{1,2,15}$ (i)
}

Received: 14 August 2018 / Accepted: 3 October 2018 / Published online: 27 October 2018

(c) The Author(s) 2018

\begin{abstract}
Purpose Lifestyle factors associated with personal behavior can alter tumor-associated biological pathways and thereby increase cancer risk, growth, and disease recurrence. Advanced glycation end products (AGEs) are reactive metabolites produced endogenously as a by-product of normal metabolism. A Western lifestyle also promotes AGE accumulation in the body which is associated with disease phenotypes through modification of the genome, protein crosslinking/dysfunction, and aberrant cell signaling. Given the links between lifestyle, AGEs, and disease, we examined the association between dietary-AGEs and breast cancer.

Methods We evaluated AGE levels in bio-specimens from estrogen receptor-positive (ER+) and estrogen receptor-negative (ER-) breast cancer patients, examined their role in therapy resistance, and assessed the ability of lifestyle intervention to reduce circulating AGE levels in ER+ breast cancer survivors.

Results An association between ER status and AGE levels was observed in tumor and serum samples. AGE treatment of $\mathrm{ER}+$ breast cancer cells altered ER $\alpha$ phosphorylation and promoted resistance to tamoxifen therapy. In a proof of concept study, physical activity and dietary intervention was shown to be viable options for reducing circulating AGE levels in breast cancer survivors.

Conclusions There is a potential prognostic and therapeutic role for lifestyle derived AGEs in breast cancer. Given the potential benefits of lifestyle intervention on incidence and mortality, opportunities exist for the development of community health and nutritional programs aimed at reducing AGE exposure in order to improve breast cancer prevention and treatment outcomes.
\end{abstract}

Keywords Advanced glycation end product · Estrogen receptor · Breast cancer · Tamoxifen resistance · Lifestyle intervention

Electronic supplementary material The online version of this article (https://doi.org/10.1007/s10549-018-4992-7) contains supplementary material, which is available to authorized users.

Marvella E. Ford

fordmar@musc.edu

David P. Turner

turnerda@musc.edu

Extended author information available on the last page of the article

\section{Introduction}

Breast cancer is the 2nd leading cause of new cancer cases in the US, where more than 3 million breast cancer survivors reside. Lifestyle behaviors such as an unhealthy diet and physical inactivity are modifiable prognostic factors that may have distinct molecular consequences on breast cancer outcomes. Despite a current consensus that exercise and a healthy diet may improve breast cancer prognosis, little is known about their positive effects on the biological pathways involved in breast tumor biology. 
Advanced glycation end products (AGEs) are reactive metabolites produced endogenously as a by-product of sugar metabolism as well as the oxidation of biological molecules [1-3]. AGEs irreversibly accumulate in our tissues causing pathogenic effects on organ homeostasis, genetic fidelity, protein function, and cell signaling cascades [1-3]. Significantly, an unhealthy diet, high in sugar, fat, and highly processed foods along with a sedentary lifestyle also contribute to the AGE accumulation pool to contribute to chronic disease development and complications [4-6]. Increases in the AGE accumulation pool lead to the perpetual activation of cancer-associated cell signaling cascades including MAPK (mitogen-activated protein kinase) and AKT (protein kinase B) leading to aberrant transcriptional activity, immune function, and oxidative stresses [7].

The pathogenic effects of AGEs are often mediated through activation of the cognate receptor for AGE (RAGE) $[1-3,6]$. RAGE knockdown in ER+ MCF7 cells decreases $17 \alpha$-ethinyl-estradiol-dependent proliferation and survival through changes in AKT, CCND1 (cyclin D1), and BCL2 (B-cell lymphoma 2) [8]. AGE-RAGE signaling promotes the activation of redox-responsive transcription factors including NFkB (nuclear factor kappa-light-chainenhancer of activated B cells) and AP-1 (activator protein 1) to increase MAPK and ERK (extracellular signal-regulated kinase) signaling [9]. Crosstalk between ER $\alpha$ and NFkB can stimulate cell proliferation and survival and contribute to tamoxifen resistance [10]. Recent data also indicate that inhibition of $E R \alpha$ by endocrine therapies such as tamoxifen may release NFKB from ER $\alpha$-driven inhibition, possibly resulting in tamoxifen resistance and NFKB-driven tumor progression [11]. Additionally, several outcome signatures derived from women treated with tamoxifen have implicated immune response as a common mechanism contributing to tamoxifen resistance [12-14].

Given the common signaling cascades involved in AGE pathogenesis and ER $\alpha$ regulation, we examined the ability of AGEs to augment ER $\alpha$ phosphorylation and tamoxifen resistance, and tested the ability of a defined lifestyle intervention program to lower AGE levels in overweight/obese post-menopausal women with non-metastatic stage I-III ER+ breast cancer.

\section{Methods}

\section{Retrospective biological samples}

For AGE analysis, serum samples were obtained from the Hollings Cancer Center Tissue Biorepository at the Medical University of South Carolina (MUSC). In total, 20 well and 20 poorly differentiated serum samples $(1 \mathrm{ml}$ of each) were selected from female breast cancer patients which had been stored between 1 and 5 years since diagnosis.

Tissue microarray's were obtained from US BioMax (Rockville, MD) and contained 96 samples of non-cancer, hyperplastic, and cancerous tissue from 48 patients. Pathological data available from each patient included tumor grade and receptor status. Tissue for mass spectrometry analysis was obtained from breast cancer patients recruited in Baltimore hospitals between 1993 and 2003, as previously described $[15,16]$.

\section{Immunohistochemical (IHC) staining}

IHC staining was performed to examine AGE levels in tissue as previously published [4]. IHC scores were calculated using the formula: intensity $\mathrm{X} \%$ positive tumor cells. Intensity staining was scored as follows: 1 -weak, 2-intermediate, 3-strong, and 4-very strong. Percent positive tumor cells were scored as follows: 1 -less than $10 \%, 2-10-30 \%, 3-30-60 \%$, and $4-60-100 \%$ positive cells by a pathologist.

\section{AGE ELISA}

To examine the levels of AGEs in serum, 96-well format Oxi-select ELISA's (Cell Biolabs, San Diego, CA) were used as directed by the manufacturer. All samples were normalized to total protein concentration [4].

\section{Mass spectrometry analysis}

Carboxymethyllysine (CML) and carboxyethyllysine (CEL) and the internal standards (IS) $\mathrm{CML}-{ }^{13} \mathrm{C}_{4} / \mathrm{CEL}^{13} \mathrm{C}_{4}$ were obtained from Sigma-Aldrich/Santa Cruz. The CML/CEL stock solutions were prepared in water as $1 \mathrm{mg} / \mathrm{mL}$ solutions. The CML/CEL calibration standards, $0.8-100 \mathrm{ng} / \mathrm{mL}$, were prepared by serial dilution of the stocks with PBS. The working IS solution $\left(10 \mathrm{ng} / \mathrm{mL}\right.$ each of the $\left.{ }^{13} \mathrm{C}_{4}\right)$ was prepared by diluting the IS stocks with $0.24 \mathrm{~N}$ trichloroacetic acid (TCA) solution. The tissue samples were wet weighted and homogenized in PBS using the Bead Ruptor (Omni), followed by centrifugation $(10 \mathrm{~min} / 16 \mathrm{~kg}) .15 \mu \mathrm{L}$ of the tissue supernatant or calibration standards were vortex mixed with $75 \mu \mathrm{L}$ IS solution. After centrifugation $(10 \mathrm{~min} / 16 \mathrm{~kg})$, the solutions were transferred to injection vials for LC/MS/ MS. LC was performed with a Shimadzu 20AC-XR system. The injection volume was $40 \mu \mathrm{L}$. Separation was achieved with a $2 \times 150 \mathrm{~mm}, 3 \mu \mathrm{m}$ SS-C1 8 column (Imtakt). Mobile phase A was $0.1 \%$ formic acid in water and mobile phase B was $50 \mathrm{mM}$ ammonium acetate/80\% methanol. The flow rate was $300 \mu \mathrm{L} / \mathrm{min}$ and peaks were eluted with a 8 -min gradient. MS/MS was performed with a TSQ Vantage triple quadrupole mass spectrometer (Thermo Fisher Scientific) 
operating in selected reaction monitoring (SRM) mode with positive electrospray ionization. The target peaks were detected using the following $\mathrm{m} / \mathrm{z}$ precursor $>$ product ions: CML (205 > 84); CML- ${ }^{13} \mathrm{C}_{4}$ (209> 88); CEL (219> 84); CEL- ${ }^{13} \mathrm{C}_{4}(223>88)$. CML and CEL in the supernatant (Y $\mathrm{ng} / \mathrm{mL}$ ) were determined using the Thermo Xcalibur software. Calibration curves, constructed by plotting the peak area ratios vs. standards, were fitted by linear regressions $\left(R^{2}=0.99\right)$. The peak area ratios were calculated by dividing the peak areas of CML or CEL by the peak area of CML${ }^{13} \mathrm{C}_{4}$ or CEL- $-{ }^{13} \mathrm{C}_{4}$, respectively.

\section{Cell culture}

MCF7 and T47D cell lines were purchased from ATCC (Manassas, VA). Cells were incubated at $37{ }^{\circ} \mathrm{C}, 5 \% \mathrm{CO}_{2}$ in their respective media. Cells were cultured up to 30 passages before being replaced from low passage stocks. Mycoplasma-negative cultures were ensured by PCR testing. Cells were monitored throughout with consistent morphology and doubling-time. T47D cells were incubated in RPMI (Fisher Scientific, Fair Lawn, NJ) with $10 \%$ fetal bovine serum (Fisher Scientific) and 1\% Penicillin/Streptomycin (Fisher Scientific). MCF7 cells were incubated in DMEM/High Glucose media (Fisher Scientific) containing 10\% FBS and $1 \%$ Penicillin/Streptomycin with the following additives: $1 \%$ MEM Non-essential Amino Acids, $1 \%$ Sodium Pyruvate, $1 \%$ Sodium Bicarbonate, and $1 \%$ insulin (all obtained from Life Technologies, Grand Island, NY).

\section{Exogenous AGE treatment}

Exogenous BSA-AGE and control BSA were produced as previously published [17]. For examination of AGE treatment, cells $(400,000)$ were seeded into each well of a 6-well plate in serum-free media overnight before treatment with AGE metabolite (50ug/ml). Effects of AGE treatment on the phosphorylation of ER $\alpha$, AKT, and ERK was assessed by Western blot as indicated below. Pharmacological targeting of the MAPK/ERK and PI3K/AKT pathways in the presence of AGE was achieved in serum-free media using the molecular inhibitors U0126 (ERK) and LY294002 (AKT) (Cell signaling Technology, Danvers, MA) at a concentration of $10 \mathrm{uM}$ for $12 \mathrm{~h}$ before exposure to AGE metabolites. To examine the effects of AGE metabolite on tamoxifen resistance, cells $(3,000)$ were seeded into each well of a 96-well plate and were treated with the active metabolite of tamoxifen, 4-hydroxytamoxifen $(0,10 \mu \mathrm{M})$ (Sigma-Aldrich, St. Louis, MO) in combination with varying doses of AGEs $(0,5 \mu \mathrm{g} / \mathrm{mL}, 10 \mu \mathrm{g} / \mathrm{mL}, 50 \mu \mathrm{g} / \mathrm{mL})$. After 24,48 , and $72 \mathrm{~h}$, SRB staining was used to quantify cell growth as described previously [18].

\section{Western Blot analysis}

For isolation of total protein, cells at $70-80 \%$ confluence were washed twice with ice cold 1xPBS, and were lysed in radio-immunoprecipitation assay (RIPA) buffer containing protease and phosphatase inhibitors (Sigma). Equal amounts of total protein $(50 \mu \mathrm{g})$ were resolved by $10 \%$ SDS-PAGE and subjected to Western blot analyses using ECL system (Pierce-Fisher Scientific, Rockford, IL). Total protein lysates were examined using primary antibodies against total ER $\alpha$, phosphorylated ER $\alpha$-ser118 (p-ER $\alpha(\operatorname{ser} 118)$ ), phosphorylated ER $\alpha$-ser167 (p-ER $\alpha$ (ser167)), total ERK, phosphorylated-ERK (pERK), total AKT, phosphorylatedAKT (pAKT), and GAPDH (all obtained from Cell Signaling Technology).

\section{Intervention design and dietary assessment}

See supplementary methods.

\section{Statistical analysis}

See supplementary methods.

\section{Results}

\section{AGE levels are elevated in ER+ breast cancer patients}

Breast tumor microarrays were stained using antibodies specific for AGE. Staining intensity in tumor tissue varied by stage and differentiation (Fig. 1). Highest staining for epithelial AGE was observed in carcinoma and then hyperplasia tissue when compared to non-cancer tissue specimens (Fig. 1a). In contrast, stromal AGE in the same tissue samples was highest in non-cancer and hyperplasia tissue (Fig. 1b). In a separate set of serum samples obtained from the MUSC biorepository, analysis by ELISA shows that circulating AGE levels are higher in serum from patients with well-differentiated tumors compared to poorly differentiated (Fig. 1c). When stratified by ER status, ER+ patients had significantly higher circulating AGE levels than ER-patients (Fig. 1d).

\section{$\mathbf{N}^{\varepsilon}$-carboxymethyllysine and $\mathbf{N}^{\varepsilon}$-carboxyethyllysine are elevated in breast tumors}

Levels of CML and CEL were assessed in a separate set of 19 non-cancerous and 18 cancerous breast tissue samples using liquid chromatography-tandem mass spectrometry (LC/MS/MS). Compared to non-cancerous tissue, both CML (Fig. 1e) and CEL (Fig. 1f) levels were elevated in the 
Fig. 1 AGE levels are elevated in ER+ breast cancer patients. a Quantification of epithelial AGE levels in breast normal and tumor tissue using IHC staining. b Quantification of stromal AGE levels in breast tumor tissue using IHC staining. c Quantification of circulating AGE levels, analyzed by ELISA, in serum from breast cancer patients stratified by well and poorly differentiated tumors. d Quantification of circulating AGE levels, analyzed by ELISA in serum from breast cancer patients stratified by ER status. e Quantification of CML levels in non-cancer and breast tumor tissue using LC/MS/ MS. f Quantification of CEL levels in non-cancer and breast tumor tissue using LC/MS/ MS. g Quantification of CML levels, analyzed by LC/MS/MS in non-cancer and breast tumor tissue stratified by ER status. $\mathbf{h}$ Quantification of CEL levels, analyzed by LC/MS/MS in noncancer and breast tumor tissue stratified by ER status

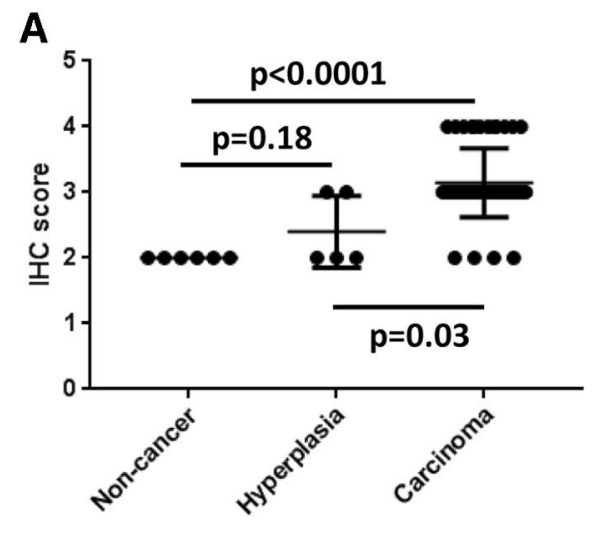

B
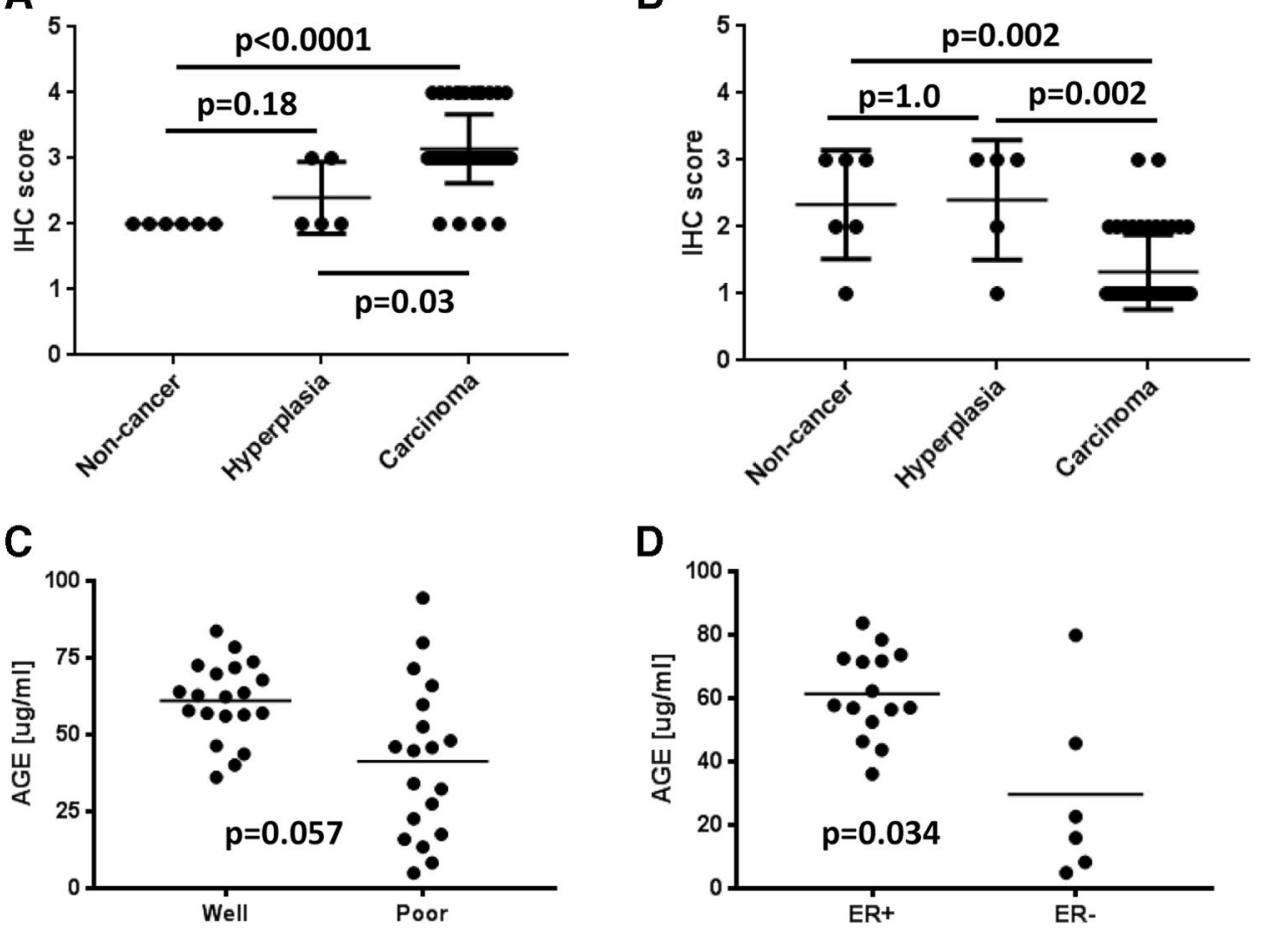

D

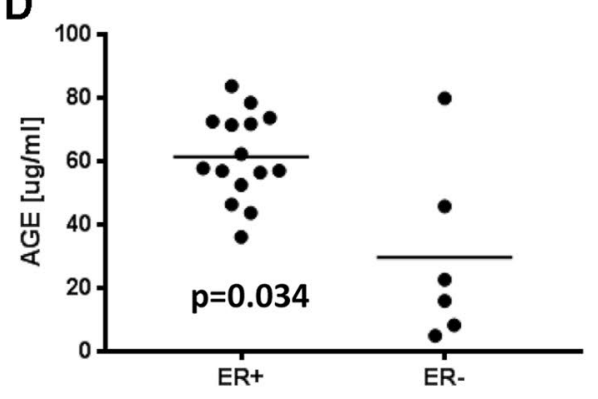

E
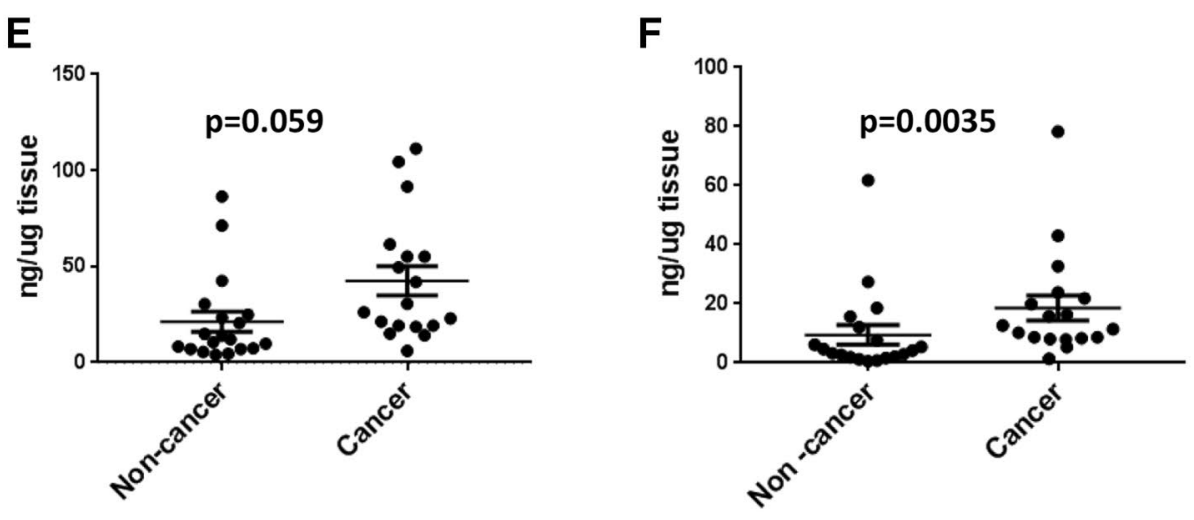

G

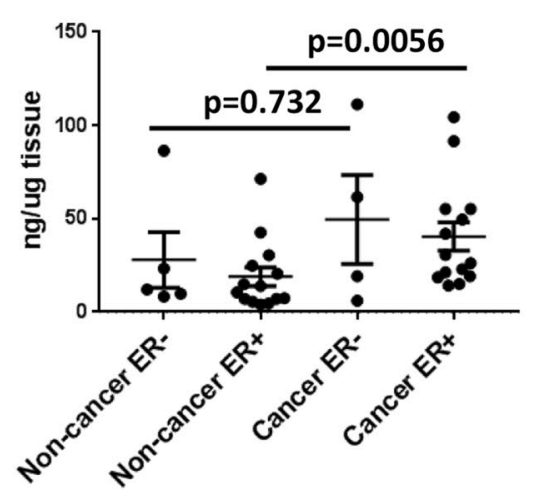

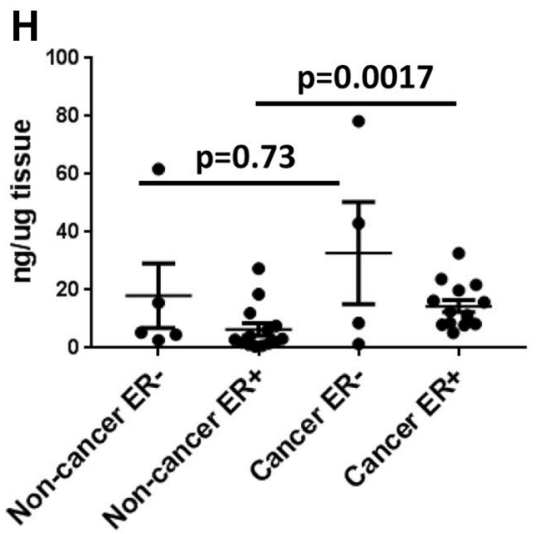

tumor tissues. Average levels of CML and CEL in the tumor samples were $42.44 \mathrm{ng} / \mu \mathrm{g}$ and $18.55 \mathrm{ng} / \mu \mathrm{g}$, respectively, compared to $21.29 \mathrm{ng} / \mu \mathrm{g}$ and $9.468 \mathrm{ng} / \mu \mathrm{g}$ in non-cancerous tissue. When stratified by ER status both CML and CEL levels were higher in ER+ and ER- tumor tissue compared to non-cancerous but this only reached statistical significance 
for the ER+ comparison (Fig. 1g, h). Collectively these data show that both CML and CEL are elevated in the tumor of breast cancer patients and may trend towards higher levels in $\mathrm{ER}+$ patients.

\section{AGE treatment activates pathways associated with ER regulation and tamoxifen resistance}

We first examined whether AGE stimulates AKT and ERK activity in ER+ breast cancer cells. Cells were treated with BSA-AGE $(50 \mu \mathrm{g} / \mathrm{mL})$, and the effects on AKT (ser473) and ERK phosphorylation (ser202/tyr204) assessed. Control cells were treated with BSA [17]. We observed a significant increase in both AKT and ERK phosphorylation in both MCF7 (Fig. 2a) and T47D (Supplementary Fig. 1a) cell lines in response to AGE treatment in a time-dependent manner.
Phosphorylations of ser1 18 and ser167 within the ligandindependent activation domain of ER $\alpha$ are two residues emerging as potential predictive markers for patient response to tamoxifen [19, 20]. MCF7 and T47D cells were treated with $50 \mathrm{ug} / \mathrm{mL}$ of AGEs for $30 \mathrm{~min}$ and were then examined for phosphorylation of $\mathrm{ER} \alpha$ at residues ser118 and ser167. $100 \mathrm{nM}$ estradiol, one of the key estrogenic ligands for the receptor, was used as a positive control to ensure optimization of phospho-specific antibodies. In both cell lines and at both residues, we found a significant increase in phosphorylation of ER $\alpha$ following AGE treatment when compared to untreated control with no overall change in total ER $\alpha$ levels (Fig. 1b and Supplementary Fig. 1b). We also examined the influence of AGE treatment on the phosphorylation of ER $\alpha$ at ser167 over a time course of $1 \mathrm{~h}$ in MCF7 and T47D cells and observed that the AGE-mediated phosphorylation
Fig. 2 AGE treatment activates pathways associated with ER regulation and tamoxifen treatment. a Western blot analysis of time-dependent AKT and ERK phosphorylation after treatment with AGE (50ug/ $\mathrm{mL}$ ) in MCF7 breast cancer cells. b Western blot analysis of ER $\alpha$ phosphorylation after treatment with AGE $(50 \mathrm{ug} / \mathrm{mL})$ in MCF7 breast cancer cells. c Western blot analysis of AKT and ERK phosphorylation after treatment with AGE $(50 \mathrm{ug} / \mathrm{mL})$ in MCF7 cells in the presence of AKT inhibitor. d Western blot analysis of AKT and ERK phosphorylation after treatment with AGE $(50 \mathrm{ug} / \mathrm{mL})$ in MCF7 cells in the presence of ERK inhibitor. e Cytotoxicity assay of MCF7 cell proliferation after treatment with tamoxifen (10uM) in the presence of increasing AGE concentration. f Cytotoxicity assay of MCF7 cell proliferation after treatment with tamoxifen $(20 \mu \mathrm{M})$ in the presence of increasing AGE concentration
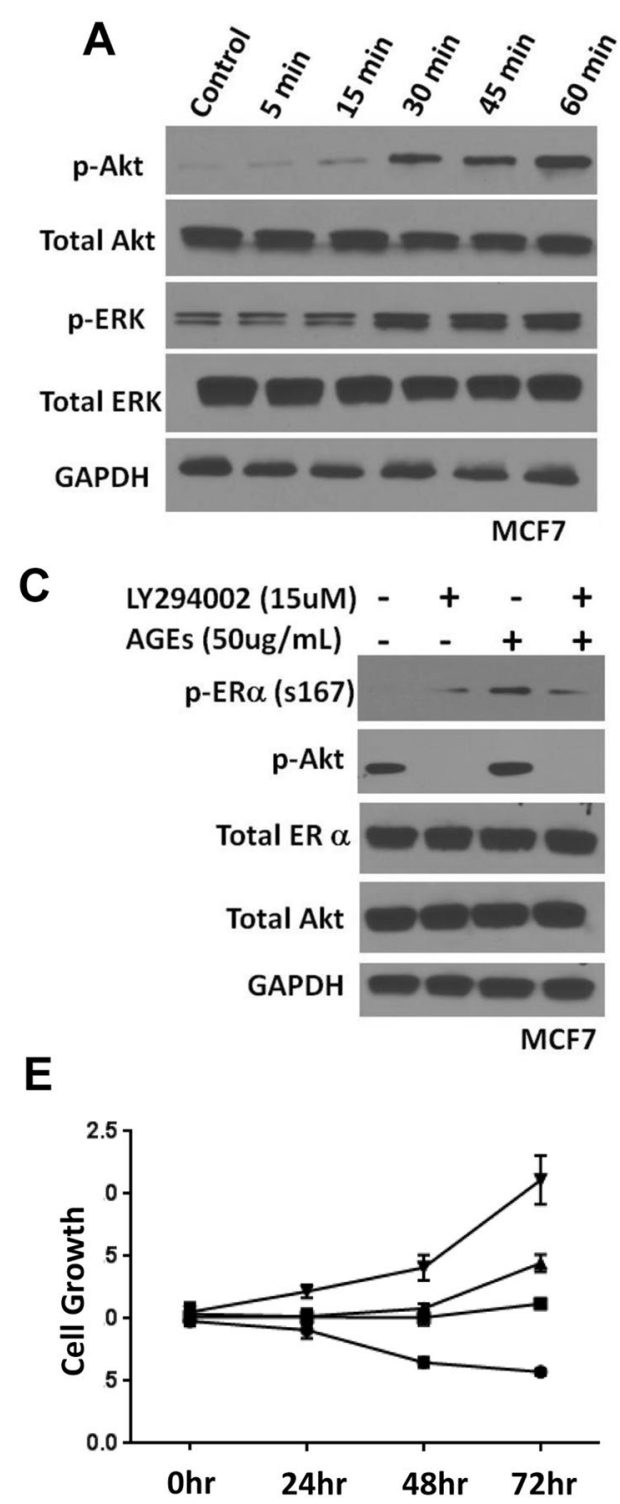
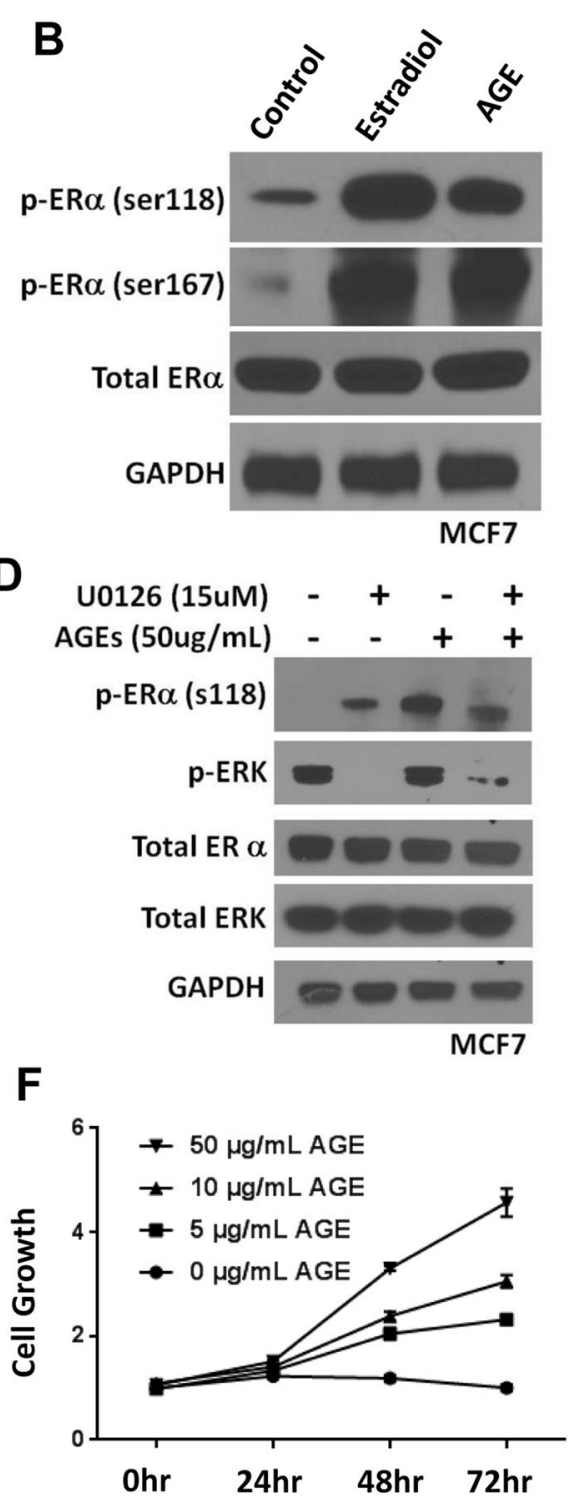
of ER $\alpha$ is transient in nature with a peak around 15-30 min following initial treatment (Supplementary Fig. 1c, d).

To determine if ERK and AKT signaling are required for AGE-mediated ER $\alpha$ phosphorylation, both ERK and AKT pathways were pharmacologically inhibited in the presence of AGE. In MCF7 cells, inhibition of AKT with Ly294002 and inhibition of ERK with the MEK inhibitor U0126 significantly reduced phosphorylation of ER $\alpha$ ser167 (Fig. 2c) and ser1 18 (Fig. 2d), respectively, in the presence (50ug/mL) of AGE metabolite. Similar results were observed in T47D cells treated in the same manner (Supplementary Fig. 1e, f).

To explore a potential role for AGE metabolites in tamoxifen resistance, we treated MCF7 and T47D cells with varying levels of AGEs in the presence of tamoxifen $(10 \mu \mathrm{M})$. Cells were cultured for 24,48 , and $72 \mathrm{~h}$ and cell proliferation was assessed using a sulforhodamine B (SRB) colorimetric assay [18]. The proliferation of cells in the absence of AGE was inhibited by treatment with tamoxifen in both cell lines as expected (Fig. 2e, f). When tamoxifen was added to the cells in the presence of increasing concentration of AGE (from 5 to $50 \mu \mathrm{g} / \mathrm{ml}$ ), a dose-dependent restoration of proliferation was observed in both MCF7 and T47D cells (Fig. 2e, f). The data outlined in Fig. 2 identify a mechanistic link between sugar-derived metabolites, AGEs, and ER $\alpha$ regulation which may provide a direct biological consequence of poor lifestyle that may directly impact tamoxifen efficacy.

\section{Lifestyle intervention reduces the levels of AGE in the circulation of ER+ breast cancer survivors}

In a proof of concept pilot study, we tested the ability of a defined lifestyle intervention to lower AGE levels in ten overweight/obese post-menopausal women with non-metastatic stage I-III ER+ breast cancer. Characteristics for the ten participants are summarized in Table 1. The intervention consisted of a focused 11-week physical activity (PA) and dietary counseling intervention that took place within the established clinical setting of the Medical University of South Carolina (MUSC) cardiopulmonary rehabilitation center (Cardiac-Rehab) (Fig. 3a) (Supplementary Methods).

The pilot study showed a favorable $67 \%$ consent rate. Of the 15 enrolled patients, 12 completed the 11-week program; 2 participants were later found to be ineligible because of past weight loss surgery that was not reported at enrollment (and were not included in this analysis). A further 3 dropped out due to competing medical conditions and unwillingness to continue resulting in a $73 \%$ adherence rate. Overall adherence to the weekly exercise sessions at cardiac rehab was $82.3 \%$ with $50 \%$ of participants showing $100 \%$ adherence to the twice weekly visits. A modest but general trend of improvement was observed in clinical and laboratory measures as a result of the 11-week intervention (Table 2 and Supplementary Table 1). Statistical significance was observed for diastolic blood pressure $(p=0.01)$ and lipid levels $(p=0.05)$. An analysis of the Fitbit data showed a significant increase in overall very active minutes (Fig. 3b) which coincided with a concurrent increase in average calories burned (Fig. 3c) when compared to baseline assessments, demonstrating the potential health benefits of the study intervention for cancer survivors. Seven (70\%) participants showed reduced calorie intake as a result of the dietary intervention while three (30\%) increased their calorie intake (Fig. 3d). While some participants showed individual reductions (Supplementary Fig. 2a-c), an analysis of aggregate diet composition showed no significant difference in fat, carbohydrate, and protein composition (Supplementary Fig. 2d). Maximal oxygen consumption (VO2 max) was significantly increased at the end of the intervention when compared to baseline levels (Fig. 3e). An assessment of daily dietary-AGE content was carried out on the basis of 7-day food records; the assessment was estimated from a database of $\sim 560$ foods and was expressed as AGE Equivalents (Eq/ day) (1 AGE equivalent $=1000$ kilounits) [21]. Dietary-AGE content was consistently reduced in the participants taking part in the intervention (Fig. 3f). Compared to baseline values, nine participants (90\%) showed significant reductions in dietary-AGE intake at week 8 , which maintained at week 11 for eight participants (80\%). In general, participants that showed significant reductions in dietary-AGE intake at week 8 and week 11 also showed significant reductions in circulating AGE levels when fasting serum samples were analyzed by ELISA (Fig. 4a). Only two patients had higher circulating AGE levels at week 11 than baseline. Median AGE levels at baseline were $53 \mathrm{ug} / \mathrm{ml}$ compared to $23 \mathrm{ug} / \mathrm{ml}$ at week 8 and $38 \mu \mathrm{g} / \mathrm{ml}$ at week 11 (Fig. 4b). These findings represent an about 30-60\% reduction in the AGE levels. An examination of circulating AGE levels at 13 weeks post intervention ( 24 weeks) showed a return to pre-intervention levels in all participants (Fig. 4C). Interleukin 6 (IL6) and C-reactive protein (CRP) are often used to assess inflammatory changes induced by diet and exercise. An analysis of IL6 (Fig. 4d) and CRP (Fig. 4e) levels by ELISA in the same AGE-assessed samples revealed no significant differences at any time point.

\section{Discussion}

Given the increasing consumption of dietary-AGEs due to their inherent relationship with a Western lifestyle, it is important to elucidate their potential contribution to the carcinogenic process. Lifestyle and pharmacological interventions that lower AGE levels may then be viable options to reduce breast cancer incidence and improve prognosis in those living with breast cancer. We have identified a mechanistic link between AGEs and ER $\alpha$ regulation which may 
Table 1 Participant information for the lifestyle intervention

\begin{tabular}{|c|c|}
\hline Characteristic & $n(\%)$ \\
\hline Age, mean (range) & $56(46-68)$ years \\
\hline Age at diagnosis, mean (range) & 57 (46-67) years \\
\hline \multicolumn{2}{|l|}{ Race } \\
\hline European American & $6(60)$ \\
\hline African American & $4(40)$ \\
\hline \multicolumn{2}{|l|}{ Education level } \\
\hline$<12$ years & $1(10)$ \\
\hline High school graduate or GED & $1(10)$ \\
\hline Some college & $5(50)$ \\
\hline College graduate & $1(10)$ \\
\hline Postgraduate & $2(20)$ \\
\hline \multicolumn{2}{|l|}{ Diabetes } \\
\hline Yes & $1(10)$ \\
\hline No & $9(90)$ \\
\hline \multicolumn{2}{|l|}{ Time since diagnosis (from date of study registration) } \\
\hline $1-6$ months & $4(40)$ \\
\hline $7-12$ months & $5(50)$ \\
\hline $13-18$ months & $0(0)$ \\
\hline 19-24 months & $0(0)$ \\
\hline $25-36$ months & $1(10)$ \\
\hline \multicolumn{2}{|l|}{ Tumor stage } \\
\hline IA & $5(50)$ \\
\hline IIA & $2(20)$ \\
\hline IIB & $2(20)$ \\
\hline IIIA & $1(10)$ \\
\hline \multicolumn{2}{|l|}{ Menopausal status } \\
\hline Pre-menopausal & $1(10)$ \\
\hline Post-menopausal & $9(90)$ \\
\hline \multicolumn{2}{|l|}{ Hormone status } \\
\hline ER/PR+Her2- & $10(10)$ \\
\hline \multicolumn{2}{|l|}{ Treatment type all participants had had surgery apart from 1} \\
\hline Radiation therapy only & $1(10)$ \\
\hline Hormone therapy only & $1(10)$ \\
\hline Radiation therapy + chemotherapy & $1(10)$ \\
\hline Radiation therapy + hormone therapy & $4(40)$ \\
\hline Radiation therapy + chemotherapy + hormone therapy & $3(30)$ \\
\hline
\end{tabular}

Table of patient characteristics

$G E D$ general education development, $E R$ estrogen receptor, $P R$ progesterone receptor, $H E R$ human EGF receptor provide a direct biological consequence of poor lifestyle that may directly impact tamoxifen efficacy.

About $70 \%$ of all invasive breast cancers express the estrogen receptor, making it of utmost importance to create more effective treatments, reduce resistance to current treatments, and improve outcomes through lifestyle interventions for these patients. The data presented suggest that AGE levels may be highest in ER+ tumors when compared to ER - and that, at least in vitro, elevated AGE levels can inhibit the growth inhibitory effects of tamoxifen. Studies have shown an association between certain estrogenindependent phosphorylation sites on $\mathrm{ER} \alpha$ and tamoxifen resistance [19, 20]. Here, we have shown that two of these residues, ser118 and ser167, are activated in response to AGE exposure and that AGE treatment reduces cell sensitivity to tamoxifen treatment. By identifying an AGEmediated effect on sensitivity to this drug, we can add to the existing knowledge base that is reinforcing the need for more personalized medicine in cancer, including implementation of specific lifestyle changes. By characterizing 


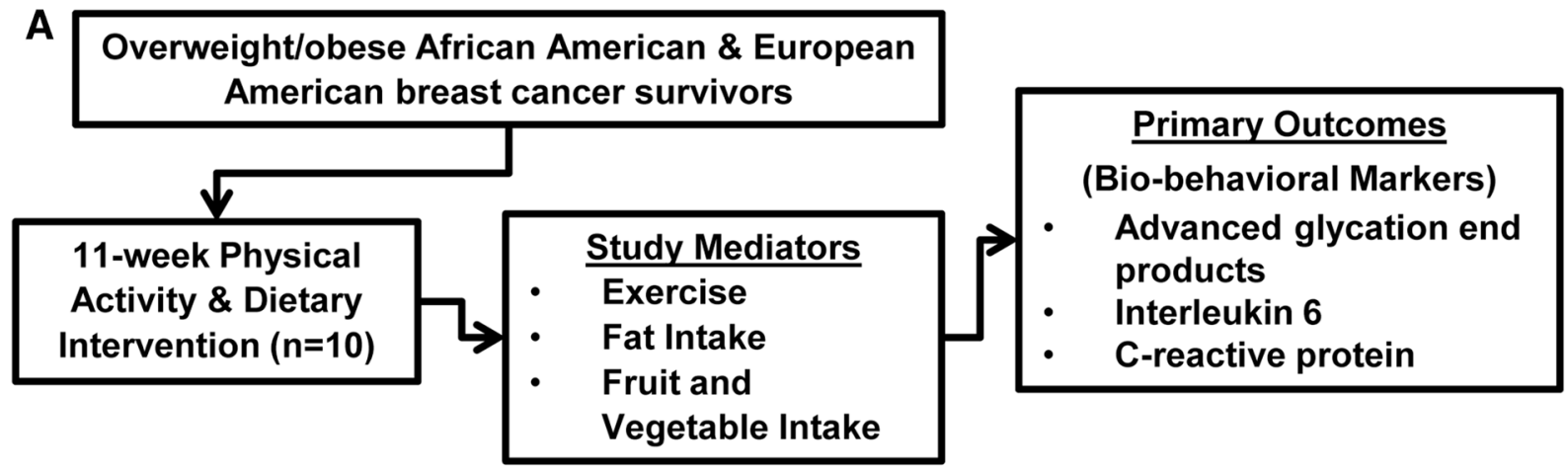

B

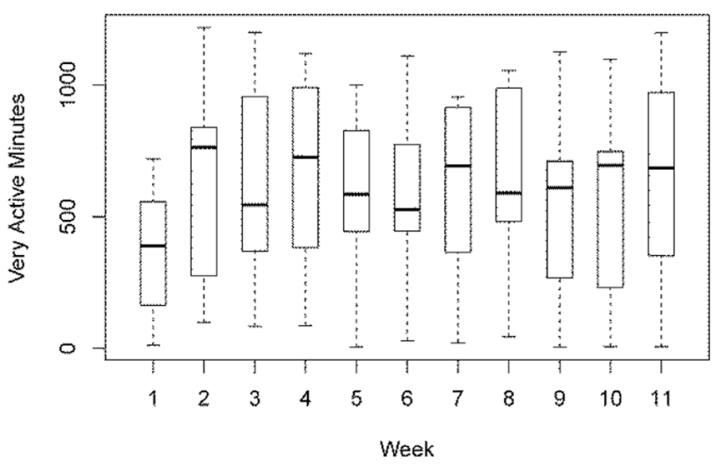

D

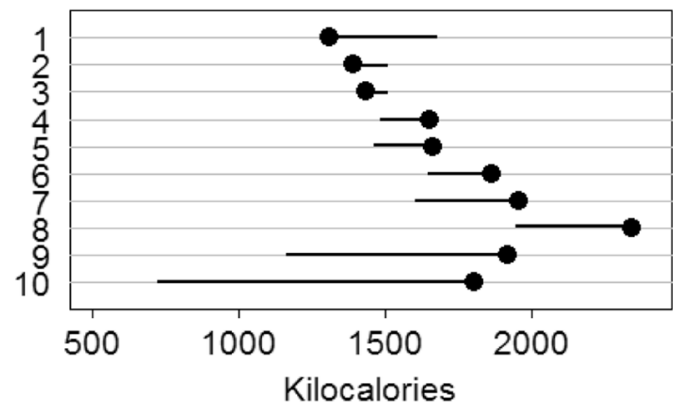

C

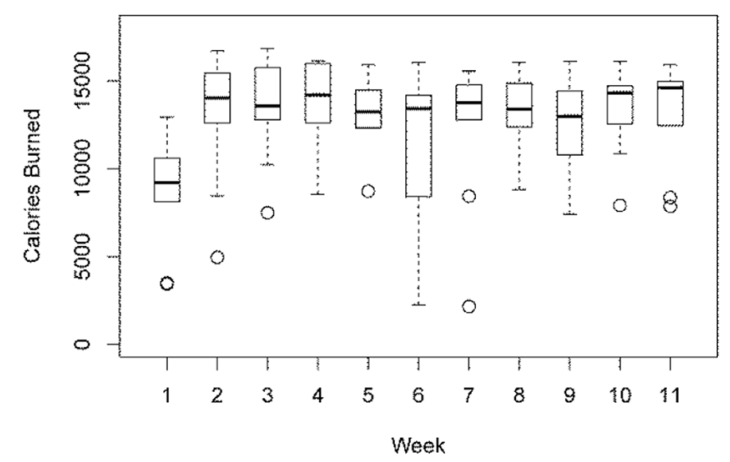

E

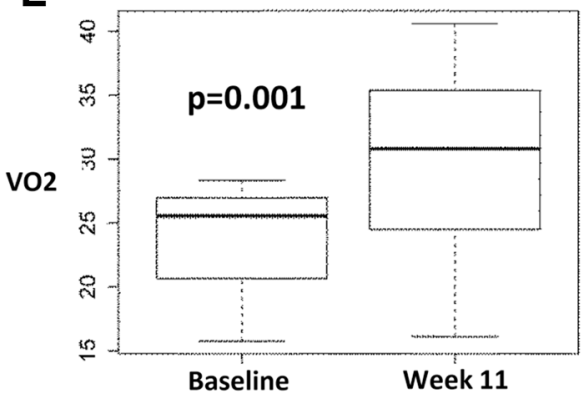

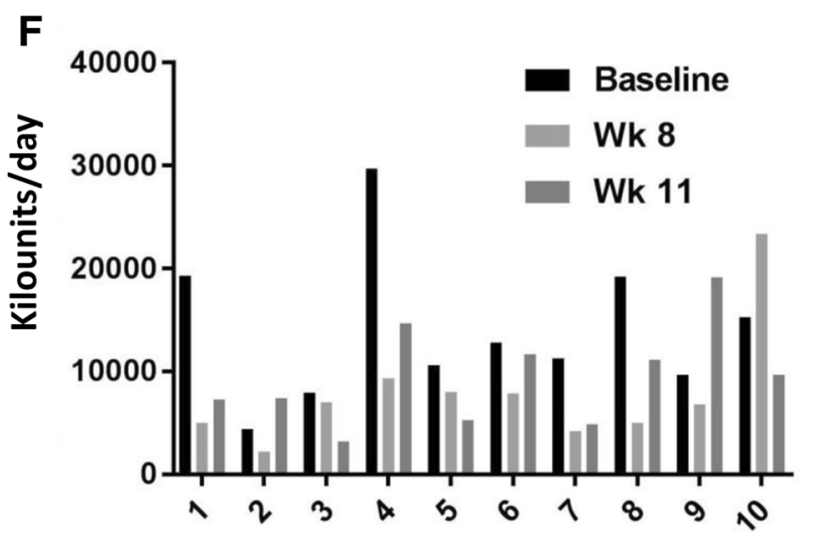

Participant 
4Fig. 3 Lifestyle intervention reduces dietary-AGE intake in ER+ breast cancer survivors. a Conceptual Framework for the PA and dietary intervention. b Average very active minutes achieved by participants during the 11-week lifestyle intervention as assessed from Fitbit data. c Average calories burned by participants during the 11-week lifestyle intervention as assessed using 7-day food records. d Calorie intake for each participant as assessed using 7-day food records. e Average VO2 max at baseline and completion of the 11-week lifestyle intervention. f Dietary-AGE intake per participant at baseline, week 8 , and week 11 of the lifestyle intervention as assessed using 7-day food records

a functional role of AGEs in the development of tamoxifen resistance, we suggest that targeted therapies for this type of cancer can potentially become more effective through modification of diet, increased physical activity, and/or through pharmacological strategies to reduce AGE accumulation. While this in vitro work is an important foundation in investigating a role for AGEs in tamoxifen resistance, it fails to address the complexity of the tumor microenvironment and intracellular signaling. However, it is still an important first step and future studies will address the importance of AGE in mediating resistance to tamoxifen especially when those studies use in vivo mouse models to validate the AGE-mediated effects we observed in our cell line studies.

Many of the foods that we consume contribute to the AGE accumulation pool in the body [21-24]. The Western lifestyle consisting of foods high in sugar, protein, and fat and low in fruit, grains, and vegetables is particularly AGE laden and associated with an increased chronic disease risk [21-24]. AGE and AGE precursors are naturally present in uncooked meats; frying, grilling, or roasting leads to a significant increase in AGE formation as we cook our foods $[5,6]$. Similarly, food processing and manufacturing also accelerates AGE formation and food manufacturers regularly add AGEs directly during processing in order to improve food appearance and taste 21 .

A major goal of the proof of concept lifestyle intervention was to assess the clinical infrastructure of cardiac rehab as a platform for breast cancer survivors. This clinical setting was chosen because the goal of cardiac rehab is to provide supervised exercise training to enable patients with cardiovascular disease to achieve their optimal physical functioning [25-27]. The study shows a favorable $67 \%$ consent rate and $73 \%$ adherence rate and resulted in an increased level of PA, promoted a healthier diet, and was shown to be a successful strategy for reducing circulating AGE levels in breast cancer patients. This study identifies AGEs as a ubiquitous molecular indicator of lifestyle change. Both dietary and circulating AGE levels were consistently lowered by the cardiac rehab lifestyle intervention, while we observed no change in the more recognized bio-behavioral markers IL6 and CRP.

In summary, AGE metabolite levels may represent a sensitive ubiquitous bio-behavioral marker for the molecular assessment of lifestyle change. Dietary-AGE restriction has been previously shown to reduce circulating AGE levels in patients with chronic kidney disease, metabolic syndrome, and diabetes [28]. As the intervention for this study was a proof of concept exercise, the results should be interpreted with caution due to a number of limitations including the small cohort of participants in the intervention which limits the ability to make conclusions beyond the feasibility of the intervention. However, the present study may provide a defined framework for future studies seeking to improve cancer outcomes and quality of life among cancer survivors across wide racial/ethnic, geographic, and socioeconomic strata. 
Table 2 Average pre- and post- intervention clinical and laboratory characteristics

Pre-intervention mean (range)

Hip circumference $(\mathrm{cm})$

Waist:hip ratio $(\mathrm{cm})$

Body mass index $\left(\mathrm{kg} / \mathrm{m}^{2}\right)$

Systolic blood pressure $(\mathrm{mmHg})$

Diastolic blood pressure $(\mathrm{mmHg})$

Laboratory characteristics ${ }^{\mathrm{a}}$

Glucose $(\mathrm{mg} / \mathrm{dl})^{\mathrm{b}}$

Insulin $(\mathrm{mcILI} / \mathrm{m} 1)^{\mathrm{c}}$

Lipid Levels $(\mathrm{mmol} / \mathrm{L})^{\mathrm{d}}$

Hemoglobin A1C (mmolimo1) ${ }^{\mathrm{e}}$

HOMA-insulin resistance ${ }^{\text {f,g }}$
$116.7(106.7-125.0)$

$164.3(160.0-172.7)$
$90.9(75.3-110.3)$
$80(67-95)$
$17(16-20)$
$107.0(94.0-124.0)$
$116.7(106.7-125.0)$
$0.90(0.83-0.95)$
$33.8(27.5-43.09)$
$137(117-166)$
$84(74-100)$

117 (92-139)

$24.4(11.7-43.8)$

200 (166-234)

$6.1(5.1-7.6)$

$7.2(3.5-15.0)$
Post-11-week intervention mean (range)

$164.3(160.0-172.7)$

89.5 (71.5-109.5)

77 (62-88)

18 (16-20)

$105.6(91.4-125.1)$

$116.8(108-141.0)$

Paired difference

mean

$p$ value (paired $t$ test)

$0.90(0.83-1.02)$

$33.2(26.4-42.8)$

129 (112-144)

$76(62-94)$

0.0

$-1.4$

0.34

$-2.9$

0.31

$+0.9$

0.17

$-1.1$

0.50

0.1

0.97

0.0

0.55

$-0.5$

0.30

$-7.3$

0.06

$-8.2$

0.01

$117(102-141)$

$+1.1$

0.65

$17.1(9.1-31.4)$

$-4.5$

0.09

$186(146-236)$

$-10.6$

0.049

$6.0(5.3-7.2)$

$-0.1$

0.65

$5.1(2.8-10.2)$

0.11

The bold numbers are statisticaly significant

Table of clinical and laboratory measures taken during the intervention

a24-h fasting blood draws

${ }^{\mathrm{b}}$ Glucose: pre-intervention missing $=1(n=9)$

${ }^{\mathrm{c}}$ Insulin: pre-intervention missing $=3(n=7)$; post-intervention missing $=1(n=9)$

${ }^{\mathrm{d}}$ Lipid levels: post-intervention missing $=1(n=9)$

${ }^{\mathrm{e}}$ Hemoglobin A1C: post-intervention missing $=1(n=9)$

${ }^{\mathrm{f}}$ HOMA-insuling resistance: pre-intervention missing $=4(n=6)$; post-intervention missing $=1(n=9)$

${ }^{g}$ HOMA-Insulin resistance formula: (insulin $\times$ glucose) $/ 405$ 
Fig. 4 Lifestyle intervention reduces the levels of AGE in the circulation of ER+breast cancer survivors. a Circulatory AGE levels per participant at baseline, week 8 and week 11 of the lifestyle intervention as assessed by ELISA. b Average AGE levels at baseline, weeks 8 and 11 for all participants of the lifestyle intervention as assessed by ELISA. $\mathbf{c}$ Percent change in circulating AGE levels at baseline, weeks 8 and 11 for all participants at of the lifestyle intervention and 13 weeks after the intervention had ended as assessed by ELISA. d Average IL6 levels at baseline and at completion for all participants of the 11-week lifestyle intervention as assessed by ELISA. e Average CRP levels at baseline and at completion for all participants of the 11-week lifestyle intervention as assessed by ELISA

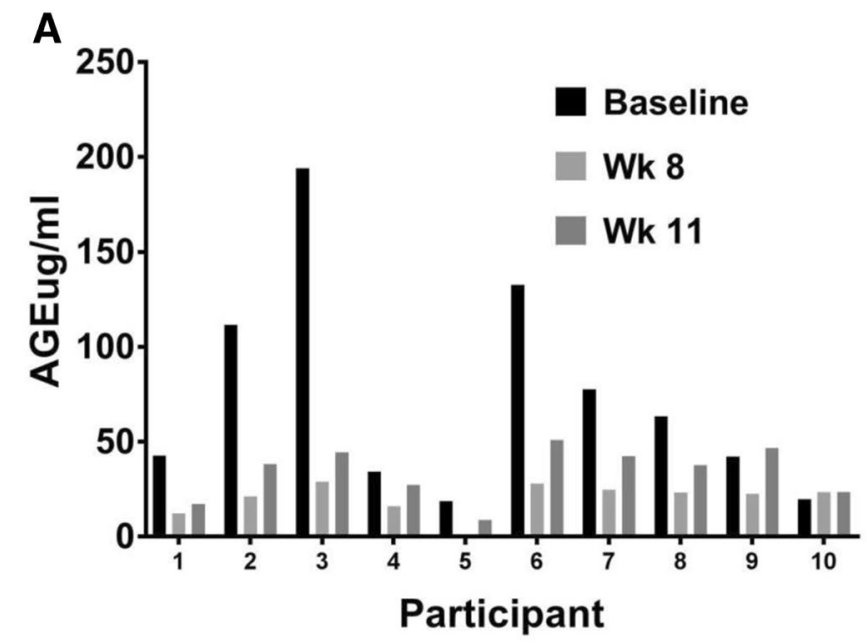

B

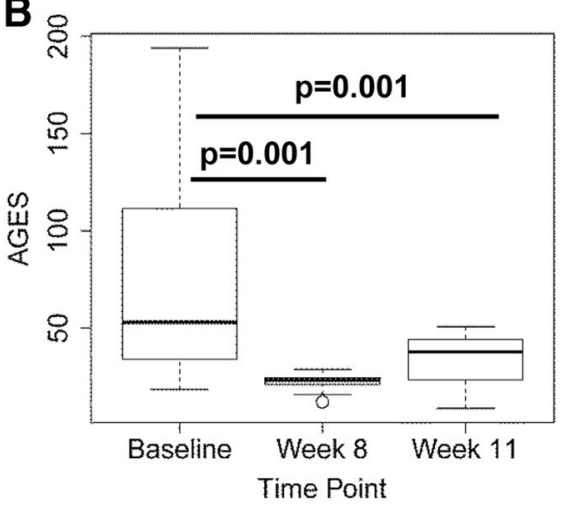

C

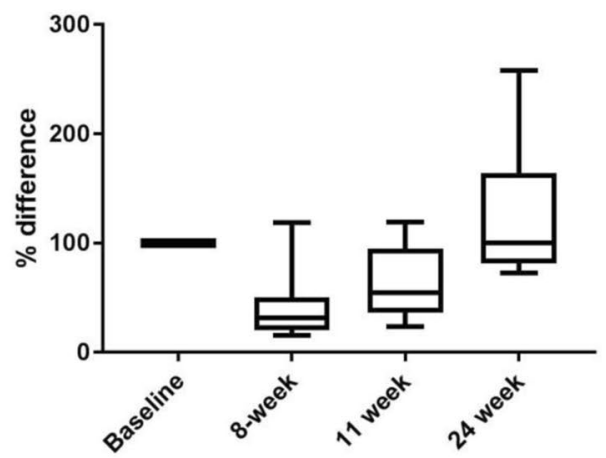

D

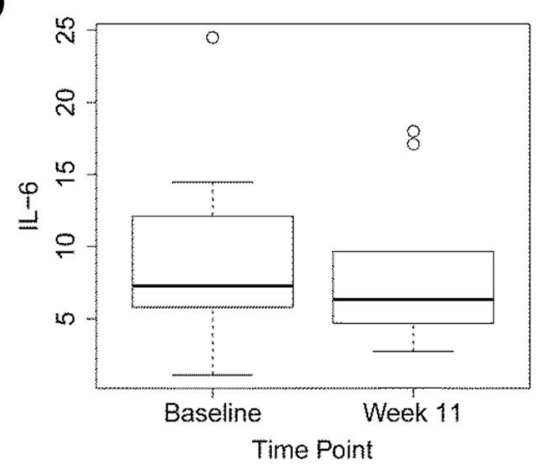

E

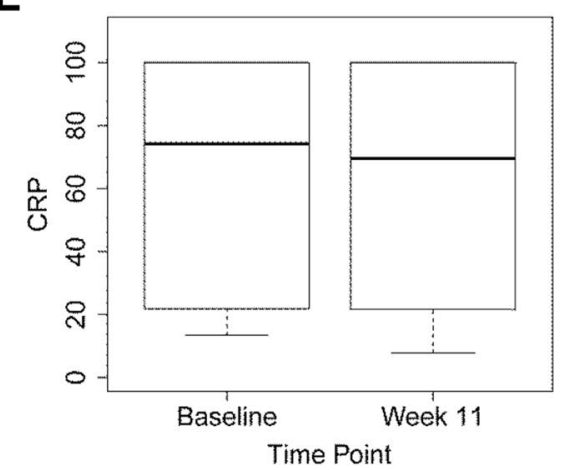

Acknowledgements Supported in part by Jill and John Chalsty; the Biostatistics Shared Resource, the Biorepository Shared Resource, Hollings Cancer Center, and pilot research funding, Hollings Cancer Center's Cancer Center Support Grant P30 CA138313 at the Medical University of South Carolina.

Funding This work was/is supported by grants from the NIH/NCI, P20 CA157071 \& U54 CA210962 to M.E. Ford; R21 CA176135 to D.P. Turner.

\section{Compliance with ethical standards}

Conflict of interest The authors declared no potential conflicts of interest with respect to the research, authorship, and/or publication of this study.

Research involving human participants and/or animals The study involved human participants, but not animals. All procedures performed in studies involving human participants were in accordance with the ethical standards of the institutional and/or national research committee and with the 1964 Helsinki Declaration and its later amendments or comparable ethical standards. 
Informed consent Each participant signed an IRB-approved, protocol specific informed consent document in accordance with federal and institutional guidelines.

Open Access This article is distributed under the terms of the Creative Commons Attribution 4.0 International License (http://creativeco mmons.org/licenses/by/4.0/), which permits unrestricted use, distribution, and reproduction in any medium, provided you give appropriate credit to the original author(s) and the source, provide a link to the Creative Commons license, and indicate if changes were made.

\section{References}

1. Singh R, Barden A, Mori T, Beilin L (2001) Advanced glycation end-products: a review. Diabetologia 44(2):129-146. https://doi. org/10.1007/s001250051591

2. Ansari NA, Rasheed Z (2010) Non-enzymatic glycation of proteins: from diabetes to cancer. Biomed Khim 56(2):168-178

3. Cho SJ, Roman G, Yeboah F, Konishi Y (2007) The road to advanced glycation end products: a mechanistic perspective. Curr Med Chem 14(15):1653-1671

4. Foster D, Spruill L, Walter KR, Nogueira LM, Fedarovich H, Turner RY, Ahmed M, Salley JD, Ford ME, Findlay VJ, Turner DP (2014) AGE metabolites: a biomarker linked to cancer disparity? Cancer Epidemiol Biomark Prev 23(10):2186-2191. https:// doi.org/10.1158/1055-9965.epi-14-0564

5. Turner DP The Role of Advanced Glycation End-Products in Cancer Disparity. In: Advances in Cancer Research. Academic Press, Cambridge

6. Turner DP (2015) Advanced glycation end-products: a biological consequence of lifestyle contributing to cancer disparity. Cancer Res 75(10):1925-1929. https://doi.org/10.1158/00085472.can-15-0169

7. Ott C, Jacobs K, Haucke E, Navarrete Santos A, Grune T, Simm A (2014) Role of advanced glycation end products in cellular signaling. Redox Biol 2:411-429. https://doi.org/10.1016/j. redox.2013.12.016

8. Lata K, Mukherjee TK (2014) Knockdown of receptor for advanced glycation end products attenuate 17alpha-ethinylestradiol dependent proliferation and survival of MCF-7 breast cancer cells. Biochimica et Biophysica Acta 1840(3):10831091. https://doi.org/10.1016/j.bbagen.2013.11.014

9. Hattori Y, Nakanishi N, Kasai K (2002) Statin enhances cytokine-mediated induction of nitric oxide synthesis in vascular smooth muscle cells. Cardiovasc Res 54(3):649-658

10. Frasor J, Weaver A, Pradhan M, Dai Y, Miller LD, Lin CY, Stanculescu A (2009) Positive cross-talk between estrogen receptor and NF-kappaB in breast cancer. Cancer Res 69(23):8918-8925. https://doi.org/10.1158/0008-5472.CAN-09-2608

11. Sas L, Lardon F, Vermeulen PB, Hauspy J, Van Dam P, Pauwels P, Dirix LY, Van Laere SJ (2012) The interaction between ER and NFkappaB in resistance to endocrine therapy. Breast Cancer Res 14(4):212. https://doi.org/10.1186/bcr3196

12. Lyng MB, Laenkholm AV, Tan Q, Vach W, Gravgaard KH, Knoop A, Ditzel HJ (2013) Gene expression signatures that predict outcome of tamoxifen-treated estrogen receptor-positive, highrisk, primary breast cancer patients: a DBCG study. PloS ONE 8(1):e54078. https://doi.org/10.1371/journal.pone.0054078

13. Vendrell JA, Robertson KE, Ravel P, Bray SE, Bajard A, Purdie CA, Nguyen C, Hadad SM, Bieche I, Chabaud S, Bachelot T,
Thompson AM, Cohen PA (2008) A candidate molecular signature associated with tamoxifen failure in primary breast cancer. Breast Cancer Res 10(5):R88. https://doi.org/10.1186/bcr2158

14. Dabydeen SA, Kang K, Diaz-Cruz ES, Alamri A, Axelrod ML, Bouker KB, Al-Kharboosh R, Clarke R, Hennighausen L, Furth PA (2015) Comparison of tamoxifen and letrozole response in mammary preneoplasia of ER and aromatase overexpressing mice defines an immune-associated gene signature linked to tamoxifen resistance. Carcinogenesis 36(1):122-132. https://doi. org/10.1093/carcin/bgu237

15. Boersma BJ, Howe TM, Goodman JE, Yfantis HG, Lee DH, Chanock SJ, Ambs S (2006) Association of breast cancer outcome with status of p53 and MDM2 SNP309. J Natl Cancer Inst 98(13):911-919

16. Prueitt RL, Boersma BJ, Howe TM, Goodman JE, Thomas DD, Ying L, Pfiester CM, Yfantis HG, Cottrell JR, Lee DH, Remaley AT, Hofseth LJ, Wink DA, Ambs S (2007) Inflammation and IGF-I activate the Akt pathway in breast cancer. IntJ Cancer 120(4):796-805

17. Takino J, Yamagishi S, Takeuchi M (2010) Cancer malignancy is enhanced by glyceraldehyde-derived advanced glycation end-products. J Oncol 2010:739852. https://doi. org/10.1155/2010/739852

18. Skehan P, Storeng R, Scudiero D, Monks A, McMahon J, Vistica D, Warren JT, Bokesch H, Kenney S, Boyd MR (1990) New colorimetric cytotoxicity assay for anticancer-drug screening. J Natl Cancer Inst 82(13):1107-1112

19. Schiff R, Reddy P, Ahotupa M, Coronado-Heinsohn E, Grim M, Hilsenbeck SG, Lawrence R, Deneke S, Herrera R, Chamness GC, Fuqua SA, Brown PH, Osborne CK (2000) Oxidative stress and AP-1 activity in tamoxifen-resistant breast tumors in vivo. J Natl Cancer Inst 92(23):1926-1934

20. Garcia-Becerra R, Santos N, Diaz L, Camacho J (2012) Mechanisms of resistance to endocrine therapy in breast cancer: focus on signaling pathways, miRNAs and genetically based resistance. Int J Mol Sci 14(1):108-145. https://doi.org/10.3390/ ijms 14010108

21. Uribarri J, Woodruff S, Goodman S, Cai W, Chen X, Pyzik R, Yong A, Striker GE, Vlassara H (2010) Advanced glycation end products in foods and a practical guide to their reduction in the diet. J Am Diet Assoc 110(6):911-916 e912. https://doi. org/10.1016/j.jada.2010.03.018

22. Uribarri J, Cai W, Sandu O, Peppa M, Goldberg T, Vlassara H (2005) Diet-derived advanced glycation end products are major contributors to the body's AGE pool and induce inflammation in healthy subjects. Ann N Y Acad Sci 1043:461-466. https://doi. org/10.1196/annals.1333.052

23. Vlassara $\mathrm{H}$ (2005) Advanced glycation in health and disease: role of the modern environment. Ann N Y Acad Sci 1043:452-460. https://doi.org/10.1196/annals.1333.051

24. Uribarri J, Cai W, Peppa M, Goodman S, Ferrucci L, Striker G, Vlassara $\mathrm{H}$ (2007) Circulating glycotoxins and dietary advanced glycation endproducts: two links to inflammatory response, oxidative stress, and aging. J Gerontol A Biol Sci Med Sci 62(4):427433. doi:62/4/427 [pii]

25. Suaya JA, Stason WB, Ades PA, Normand SL, Shepard DS (2009) Cardiac rehabilitation and survival in older coronary patients. J Am Coll Cardiol 54(1):25-33. https://doi.org/10.1016/j. jacc.2009.01.078

26. Braun LTWN, Rosenson RS (2014) Components of cardiac rehabilitation and exercise prescription. Wolters Kluwer Health. http:// www.uptodate.com/contents/components-of-cardiac-rehabilita tion-and-exercise-prescription. Accessed 24 Sept 2014 
27. Scherr JWB, Christle W, Pressler A, Wagenpfeil S, Halle M (2012) Associations between Borg's rating of perceived exertion and physiological measures of exercise intensity. Eur J Appl Physiol 113:1-9

28. Vlassara H, Cai W, Tripp E, Pyzik R, Yee K, Goldberg L, Tansman L, Chen X, Mani V, Fayad ZA, Nadkarni GN, Striker GE,
He JC, Uribarri J (2016) Oral AGE restriction ameliorates insulin resistance in obese individuals with the metabolic syndrome: a randomised controlled trial. Diabetologia 59(10):2181-2192. https://doi.org/10.1007/s00125-016-4053-x

\section{Affiliations}

Katherine R. Walter ${ }^{1}$ - Marvella E. Ford ${ }^{2,3,15} \cdot$ Mathew J. Gregoski ${ }^{4} \cdot$ Rita M. Kramer $^{3} \cdot$ Kendrea D. Knight $^{2}$.

Laura Spruill $^{1}$ - Lourdes M. Nogueira ${ }^{1}$. Bradley A. Krisanits ${ }^{1} \cdot$ Van Phan $^{1}$ - Amanda C. La Rue ${ }^{1,3,5}$.

Michael B. Lilly ${ }^{1}$ Stefan Ambs ${ }^{6} \cdot$ King Chan $^{7} \cdot$ Tonya F. Turner $^{8} \cdot$ Heidi Varner $^{2} \cdot$ Shweta Singh $^{2}$. Jaime Uribarri ${ }^{9}$. Elizabeth Garrett-Mayer ${ }^{2,3} \cdot$ Kent E. Armeson ${ }^{2,3}$. Ebony J. Hilton ${ }^{10}$ - Mark J. Clair ${ }^{11}$ • Marian H. Taylor ${ }^{11}$. Andrea M. Abbott ${ }^{12} \cdot$ Victoria J. Findlay $^{1,2} \cdot$ Lindsay L. Peterson $^{13}$. Gayenell Magwood ${ }^{14} \cdot$ David P. Turner $^{1,2,15}$

1 Department of Pathology \& Laboratory Medicine, Medical University of South Carolina (MUSC), Charleston, SC, USA

2 Department of Public Health Sciences, MUSC, Charleston, SC, USA

3 Hollings Cancer Center, MUSC, Charleston, SC, USA

4 Department of Exercise Science, College of Arts and Sciences, Campbell University, Buies Creek, NC, USA

5 Ralph H. Johnson Veterans Affairs Medical Center, Charleston, SC, USA

6 Laboratory of Human Carcinogenesis, Center for Cancer Research, National Cancer Institute, Bethesda, MD, USA

7 Cancer Research Technology Program, Leidos Biomedical Research, Frederick National Laboratory, Frederick, MD, USA

8 Dietetic Services, MUSC, Charleston, SC, USA
9 Department of Medicine/Renal Medicine, Icahn School of Medicine at Mount Sinai, New York, NY, USA

10 Department of Anesthesia and Perioperative Medicine, MUSC, Charleston, SC, USA

11 Department of Medicine, Division of Cardiology, MUSC, Charleston, SC, USA

12 Department of Surgery, MUSC, Charleston, SC, USA

13 Washington University School of Medicine, St. Louis, MO, USA

14 College of Nursing, MUSC, Charleston, SC, USA

15 James E. Clyburn Research Center Medical University of South Carolina, Charleston, SC 29425, USA 